\title{
3l index: A new method to examine the competitiveness of countries' international publication productivity
}

\author{
Feng $\mathbf{W} \mathbf{u}^{1}$ and Gordana Djurovic ${ }^{2}$ \\ ${ }^{1}$ School of Journalism and New Media, \\ Xi'an Jiaotong University, Xi'an, PEOPLE'S REPUBLIC OF CHINA, \\ ${ }^{2}$ Faculty of Economics, University of Montenegro, \\ Podgorica, MONTENEGRO \\ e-mail: wufeng8@mail.xjtu.edu.cn (corresponding author); \\ gordana@t-com.me
}

\begin{abstract}
This study proposes a new method called the 31 index to examine the competitiveness of countries' international publication productivity with indicators in three dimensions: International participation, International impact, and International leadership. Using the data (1996-2014) from the Scopus database in the communication field, we rank each country by its competitiveness score. The results reveal a polarized structure of competitiveness among all countries: The United States occupies the leading position with the highest score, Western European countries are in dominant positions with high scores, and marginalized countries (mostly in Asia, Africa, and Latin America) have lower levels of competitiveness. However, emerging countries, particularly Brazil, Russia, India, China, and South Africa (BRICS), recently have achieved great progress in international participations and impacts, that are expected to change the imbalance in international competitiveness in the near future. The regression analysis suggests that countries' economic growth status (Gross Domestic Product) and human resources (total population) have significant impacts on the competitiveness of their international publication productivity. Finally, the authors suggest that both BRICS and developed countries should increase their governments' supports to help third-world countries participate international academic cooperation.
\end{abstract}

Keywords: Communication research; International publication productivity; Research assessment; Scientometrics; Globalization; Competitiveness.

\section{INTRODUCTION}

Over the past two decades, the evaluation of publication productivity in communication research has attracted growing interest (Hickson, Stacks and Amsbary 1989). Governments employ the results of productivity evaluations to assess the impacts of public investment, formulate project-support policies, and determine funding allocation. Educational institutions rely on evaluation results to regulate discipline structures as well as to promote and reward employees (Agasisti et al. 2012). The public recognizes the reputation of academic institutions based on their evaluation results and accordingly selects degree programs and cooperation partners (Bornmarn 2012). Scholars have conducted numerous studies on the evaluation of publication productivity in the field of communication (Hickson, Stacks and Bodon 1999). However, most studies are limited to the perspectives 
of single nations (Teodorescu 2000), and only few articles have focused on countries' competitiveness in international publication productivity from a global perspective.

In the era of globalization, countries' research outputs can be divided into domestic and international publication productivity. The former includes scholarly articles written in native languages and published in domestic journals whose scope of influence is usually limited to the home country. The latter refers to papers written in an international lingua franca and published in academic journals with international influences. Scholars from various countries widely publish internationally in journals indexed in certain prestigious databases and these articles receive global attentions from researchers throughout the world (Koljatic and Silva 2001). Furthermore, the international academic community is a competitive arena, where the global scarcity of high-level talent and high-quality journal space determines countries' academic competitiveness (Fahey and Kenway 2010).

This study extends existing research with three theoretical contributions. First, past studies on the evaluation of academic productivity in the field of communication have mostly been limited to single nations or a few countries within designated local regions (Hickson et al. 1989). By shifting the perspective into a global level, this study intends to explore the characteristics of international publication productivity across countries. Second, existing research has tended to use either institutions or individuals as units of analysis (Hickson, Stacks and Amsbary 1993; Zainab 1999). This study uses nations instead of institutions or individuals as the units of analysis in an attempt to determine the competitiveness of each nation in international publication productivity. Third, the data sources used by existing studies have some limitations. For example, the Social Science Citation Index (SSCl) has been criticized for factual errors due to its narrow coverage and limited number of sample articles (Hocking, Stacks and McDermott, 2003). For analysis purposes, the present study uses Scopus, a database with a larger volume of international academic journals and articles rather than that of the $\mathrm{SSCl}$, covered by the Web of Science database.

The objectives of this study are as follows: (a) to define the competitiveness of international publication productivity in the context of globalization and establish an evaluation method using indicators in three dimensions: international participation, international impact, and international leadership; (b) to evaluate each nation's competitiveness in international publication productivity in the communication discipline based on papers included in the Scopus database from 1996 to 2014; and (c) to apply empirical methods to test the main factors influencing nations' productivity competitiveness: economic environment, research and development (R\&D) investment, human resources, and stage of education development.

\section{LITERATURE REVIEW}

\section{Evaluation Methods of Academic Productivity}

Studies on the evaluation methods of academic productivity in the communication field originated in the United States in the 1970s (Barker et al. 1979). Although the concept of competitiveness had not been proposed then, these studies represented significant progress in the "ranking-based" evaluation system of academic output (Tien and Blackburn 1996, p. 4). Today, there are two primary approaches for the evaluation methods.

First, the quantity-centered approach uses the number of published academic articles as the direct evaluation criteria. A rigorous peer-review process is required before publishing 
the papers, therefore research productivity itself includes the evaluation of research quality, and the number of papers published in academic journals by institutions and individuals, which can be used to assess their competitiveness. In the late 1980 s and early 1990s, Hickson et al. (1989) used the Index to journals in communication studies as a data source in a bibliometric analysis to evaluate the research productivity of active, prolific U.S. scholars in communication studies and their institutions. The study by Hickson et al. (1993) on the productivity of communication research in the United States from 1915 to 1995 demonstrated that top-ranked individuals published early in their careers. Additionally, the top 25 most frequently published authors of journal articles also had an average of more than 5 books in print, and the vast majority of those who had published more than 20 articles listed in the index taught in doctoral programs.

Second, the quality-centered approach considers citations of academic articles as the basis for evaluation. Garfield (1972) suggested using the number of citations to assess the quality of journals and articles, marking the birth of the concept of impact factor. Ritzberger (2008) proposed various quality evaluation indicators, including independent research capacity and cooperation intensity (for definitions, see Ritzberger 2008) and ranked the quality of economics journals accordingly. Yu and Gao (2010) suggested using indexed publications, real publications, impact-factor adjusted papers, real pages of publications, and average pages of publications as evaluation indices (for definitions, see Yu and Gao 2010) and ranked Chinese economic research institutions based on 2000-2009 publications in $\mathrm{SSCl}$ economic journals. However, research on competitiveness in international publication productivity in the communication field is scarce, indicating that existing studies fail to respond to evaluation needs in the era of globalization (Teodorescu 2000; Koljatic and Silva 2001).

\section{Definitions and Evaluation Indicators: 31 Index}

Competitiveness was originally a professional term used in economics and trade indicating companies' ability to provide superior-quality products or services at lower costs than domestic and international competitors (Aldington Report 1985). The U.S. Commission on Industrial Competitiveness extended this concept to include a country's ability to produce goods and services that meet the needs of international markets while simultaneously maintaining and expanding its real income (Tyson 1992). The National Competitiveness Council (2003) of Ireland added that competitiveness includes the countries' or companies' ability to achieve success in markets that leads to better standards for all to the definition. This study extends the concept of competitiveness in economics and trade to countries' competitiveness in international academic publication and defines it as: the power or status of a country's international publication productivity within the global academic community as determined by indicators in three dimensions: International participation, International impact, and International leadership, which is abbreviated as 3 I Index.

(a) International participation

This notion refers to the frequency of countries' participation in the international academic community and is a basic indicator of countries' academic productivity competitiveness (Jia et al. 2016). Many types of documents have been published in academic journals, but calls for submissions, meeting notices, and corrections do not belong to academic literature, and are not usually cited. This study, therefore, uses the number of citable documents to measure participation capability (Moed and Van Leeuwen 1995). 
(b) International impact

This concept refers to the degree of influence that countries' publications have in the international academic community and the attention they receive in these communities. International impact measures the quality of countries' academic output. Citations of academic articles, to a large extent, serve as countries' reputational capital to gain international recognition of academic achievement and an important representation of countries' competitiveness in productivity (Feist 1997). Three indicators are used to measure international impacts: other citations, citations per document, and the h-index. Other citations are calculated by subtracting the number of self-citations from the total citations of a country's international publications. Citations per document are the average number of citations for a published article within a time period. The $\mathrm{H}$-index is defined as the number of papers with a citation number $\mathrm{h}$ within a given period (Hirsch and Jorge 2005).

(c) International leadership

This term refers to countries' capability to play dominant or leading roles in the international academic community. Members of the international academic community have different statuses - some countries hold central positions, playing the role of leaders, while others are on the periphery, playing complementary roles (Chesterman, Ross-Smith and Peters 2003). International leadership is usually manifested in the number of international journals sponsored by a country that are recognized by the international academic community. In theory, academic journals construct a platform for fair competition among scholars from all over the world; in reality, however, they build a platform for countries to demonstrate their academic leadership capacity (Paasi 2005). Journals' editorial boards, editor-in-chiefs, and editors play the roles of academic gatekeepers, planning academic topics, developing academic rules, selecting reviewers, and constructing settings for academic agendas and thereby controlling the leading positions in the international academic community (Hodgson and Rothman 1999). English is the language closest to being the academic lingua franca, so English-language articles more easily attain international recognition. We, therefore, measure international leadership by the number of journals hosted by a country and recognized by the international academic community, as indexed in the Scopus database (most of its journals are in English).

In summary, countries' competitiveness in international publication productivity can be described in three dimensions (with five indicators). International participation arises from the number of international publications, international impact arises from the international influence of these articles, and international leadership arises from countries' leadership roles in the international academic community. In short, we propose five indicators in three dimensions that reflect the different characteristics of countries' competitiveness in international publication productivity. Generally, countries' competitiveness in international publication productivity is evaluated separately in three dimensions, but it can also be evaluated by using an integrated index. Thus, countries' competitiveness can be examined in two ways. One is from an individual perspective, analyzing performance in each dimension of competitiveness (international participation, impact, and leadership). The other one is from the integrated perspective, combining these three dimensions into one indicator to analyze countries' integrated competitiveness in international publication productivity. 


\section{Factors Influencing Competitiveness in International Publication Productivity}

Studies have shown that factors such as capital investment, human investment, and governmental policies have a certain degree of influence on countries' research output (Liu and Shen 2011). This article examines four groups of factors that may influence the competitiveness of countries' international publication productivity in the communication discipline: economic growth status, R\&D investment, human resources, and stage of education development.

\section{(a) Economic growth status}

Economic growth has a close relationship with academic research, which can be seen in the trend for shifting of global economic hotspots and often leads to knowledge transfers (Koizumi and Kopecky 1977). In general, a country's economic indicators, such as gross domestic product (GDP), GDP per capita, and share of global GDP, are closely linked to its competitiveness in academic outputs. A growing economy can provide more opportunities for academic research and increasing competitiveness; conversely, an economic slowdown leads to decreasing investment in academic research and a decline in academic competitiveness. Countries' economic growth status can be measured by GDP, GDP per capita, and share of global GDP. The present study uses the World Bank's annual economic growth reports (World Bank 2014) to obtain this information.

(b) R\&D investment.

Even in an ideal environment for economic growth, countries that do not increase R\&D investment will not improve academic research environment, which, in turn, might affect researchers' motivation and weaken academic competitiveness. In general, countries' R\&D investments are positively correlated to their competitiveness in academic productivity (Deeds 2001). The greater a country's gross expenditures on research and development (GERD) are, the higher its GERD as a GDP percentage is, which helps inspire enthusiasm among scholars and improve the competitiveness of national productivity (Berchicci 2013). Therefore, we use GERD as a percentage of GDP to measure countries' R\&D investment. The American Battelle Institute and R\&D Magazine annually publish relevant research data, and the data analyzed in this study are drawn from the 2014 Global R\&D Funding Forecast (Grueber and Studt 2015).

(c) Human resources

Human resources are a key factor influencing academic output. Broadly speaking, a country's total population is a basic factor affecting competitiveness in academic productivity (Abramo, D'Angelo and Caprasecca, 2009), and from a narrower perspective, the amount of specialized research talents in countries directly influences competitiveness (Aw, Wu, and Liu, 2007). Therefore, we use total population and the number of R\&D personnel per 1 million people to measure countries' human resources. For the former, data are collected from the 2014 report released by the Population Division of the United Nations Department of Economic and Social Affairs (2014). For the latter, data are obtained from the most recent information released by the World Bank (2014).

(d) Stage of education development.

Countries' stage of education development might affect academic productivity (Jung 2014). A higher level of education development usually indicates greater academic productivity and competitiveness. Countries' stage of education development can be measured by two indicators. One is the literacy rate, which is the percentage of people ages 15-24 years who can read, write, and understand short, simple statements about daily life. This study uses 2014 data from the UN Educational, Scientific, and Cultural Organization's (UNESCO 
Wu, F. \& Djurovic, G.

2015) annual reports on world literacy rates. The second indicator is the number of universities, both public and private, sponsored by country. The Ranking Web of Universities (RWU 2016) publishes annual reports on the distribution of the world universities, and we use the most recent data, from 2014, in this study.

\section{OBJECTIVES AND METHOD}

The goal of this study is to assess the competitiveness of countries' international publication productivity in the discipline of communication from 1996 to 2014. Firstly, we examine countries' individual performance in competitiveness in three dimensions. Thus, the first research question is: What is countries' performance in individual competitiveness in three dimensions (international participation, impact, and leadership)?

Next, we examine countries' integrated competitiveness by formulating the second research question as: What is countries' integrated competitiveness?

American and European countries have long held advantages in technology, capital, and research, occupied dominant positions in the international academic community, and controlled the global academic narrative. This has led to a western-centered academic world order (i.e., the polarization and structural imbalance of global academic output) (Biesta 2012). We aim to explore whether there were any changes in the competitiveness of international publication productivity from 1996 to 2014, prompting the third question: What are the pattern changes in the competitiveness of international publication productivity from 1996 to 2014?

Finally, this research investigates the main factors influencing countries' competitiveness in international publication productivity, and the fourth research question is posed: What are the main factors affecting countries' competitiveness in international publication productivity?

\section{Data Sources}

Countries' international publication output includes academic papers, books, conference papers, and other forms, but the present study only includes statistics on internationally published articles. The data regarding the internationally published articles of each country were retrieved from the SClmago Journal and Country Rankings (SCImago Lab 2015) on November 8,2015 . The data was originally sourced from the Scopus database released by Elsevier. This database contains mostly journals in the English language, but due to its vast collections and extensive regional coverages, it reflects the overall situation of international publications. (In 2014, Scopus indexed 240 journals in the communication field, covering 28 countries or regions, while SSCl indexed 78 journals, covering only 9 countries or regions).

\section{Units of Analysis}

This study focuses on the international publication productivity of countries or regions, therefore countries' total number of internationally published papers in the communication field was used as the units of analysis. According to the most recent report released by the World Bank (2014), the world has 230 countries or economic bodies in 2014 , and all 230 units are included in the early phases of our research. 


\section{Data Processing Procedure}

The Statistical Products and Service Solutions (SPSS) v22.0 software was used to process the data in three steps. First, descriptive analysis was conducted on the data for countries' individual competitiveness from 1996 to 2014. Second, to calculate the integrated competitiveness of each country, data normalization was conducted on each variable. The results are described as follows: $\mathrm{N} 1=\mathrm{N}$ citable documents, $\mathrm{N} 2=\mathrm{N}$ other citations, $\mathrm{N} 3=\mathrm{N}$ citations per document, N4 $=\mathrm{N}$ h-index, N5 $=\mathrm{N}$ number of journals. Principal component analysis (PCA) was performed to obtain the weight of each variable. The results are described as follows: $\mathrm{W} 1=\mathrm{W}$ citable documents, $\mathrm{W} 2=\mathrm{W}$ other citations, $\mathrm{W} 3=\mathrm{W}$ citations per document, $\mathrm{W} 4=\mathrm{W}$ h-index, $\mathrm{W} 5=\mathrm{W}$ number of journals. Then, we calculated the integrated competitiveness index (ICI) for each country according to the weight of each indicator, using the following equation:

$\mathrm{ICl}=\mathrm{N} 1 \times \mathrm{W} 1+\mathrm{N} 2 \times \mathrm{W} 2+\mathrm{N} 3 \times \mathrm{W} 3+\mathrm{N} 4 \times \mathrm{W} 4+\mathrm{N} 5 \times \mathrm{W} 5$

Finally, to test the main factors that influence countries' competitiveness in international publication productivity, we used stepwise multiple linear regressions. Insignificant independent variables (GDP per capita, GDP share, GERD, R\&D as a percentage of GDP, researchers per 1,000 people, literacy rate, and number of universities) were eliminated in each step until the regression coefficients of all the variables were significant-that is, until the remaining variables were the key factors influencing countries' competitiveness ( $p<$ 0.05). Due to incomplete data for a few smaller countries, this step included only the top 40 countries ranked according to the $2014 \mathrm{ICI}$.

\section{RESULTS}

\section{Analysis of Individual Competitiveness in Three Dimensions a) Competitiveness of International Participation.}

Our statistics indicated that, from 1996-2014, 151 countries or regions participated in the competition of international publication productivity in communication studies. However, 79 countries (mostly small and poor third-world countries) had no international publication productivity in this field. In 1996, only 39 countries participated, but by 2014, 113 countries were involved in international publication productivity. Regarding the number of internationally published articles from 1996 to 2014, there were 61,875 citable documents in the communication field. In 1996, the number of citable papers was 823 , but by 2014 , this number increased to 8,967 , a 10 -fold increase over 18 years. As a whole, the number of both countries and total citable documents published showed rapid growth.

Regarding international participation, the United States was the leader, with 25,661 international articles published from 1996 to 2014, accounting for 14.47 percent of all international articles in the communication field. The United Kingdom, Spain, Australia, and Canada were in the second tier, each with more than 2,000 international articles $(5,908,3,191,2,466$, and 2,112, respectively). The Netherlands, Germany, Brazil, France, and China were in the third tier, each with 1,000-2,000 international articles. Countries in the fourth tier - including South Korea, Taiwan, Japan, Italy, Sweden, Belgium, India, Israel, Hong Kong, and Finland - published between 600 to 1,000 papers each. These 20 countries mentioned accounted for 68.94 percent of the total global publication productivity and thus were considered to be the countries with the most powerful international participation capability (Figure 1). 
Wu, F. \& Djurovic, G.

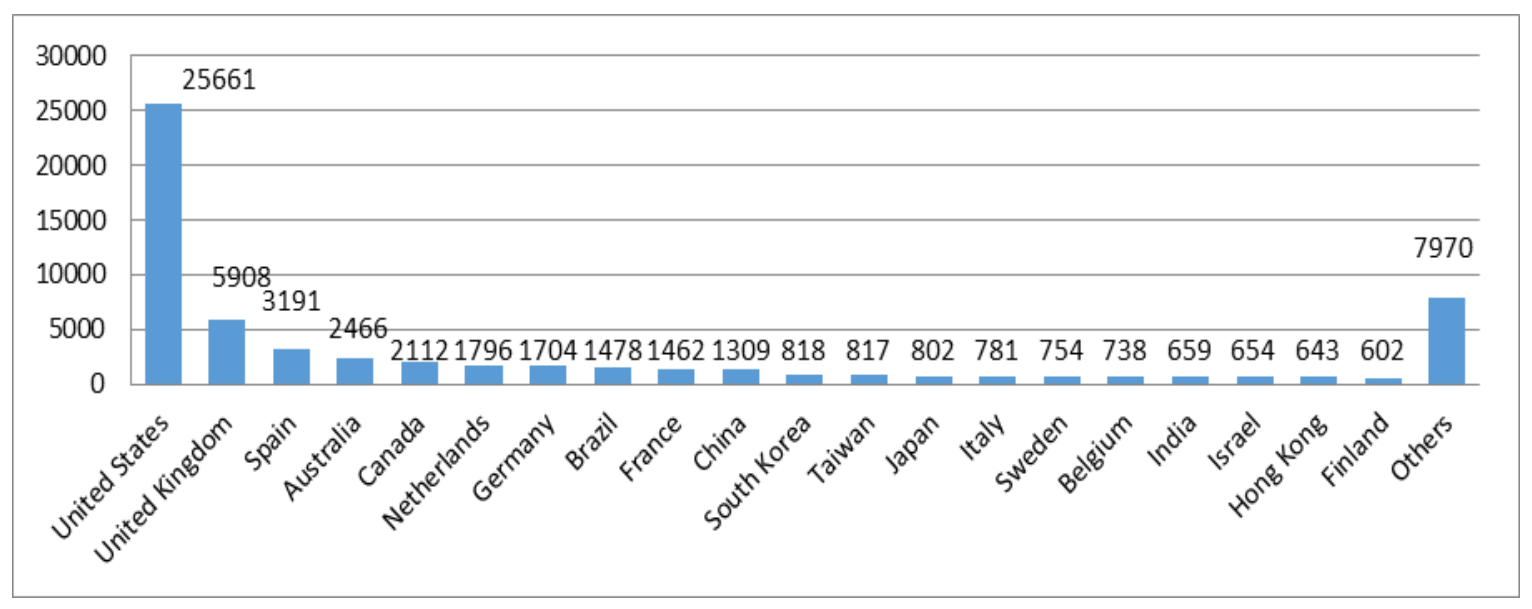

Figure 1: Total Citable Documents of Each Country (1996-2014)

\section{b) Competitiveness of International Impact}

From 1996 to 2014, papers from 130 countries had in total 271,500 of other citations, an average of 10.58 other citations per document. At the national level, the United States had the highest number of other citations in total 108,972. The United Kingdom, the Netherlands, and Canada had 10,000-40,000 other citations $(33,741,14,258,12,599$, and 11,180, respectively). Germany, South Korea, Spain, and Japan had 5,000-9,999 other citations. France, Taiwan, Sweden, Israel, and Belgium had 4,000-4,999 other citations. Hong Kong, Finland, Italy, and Singapore had 3,000-3,999 other citations. New Zealand, Denmark, Switzerland, and China had 2,000-2,999 other citations. Norway, Austria, Greece, Turkey, and South Africa had 1,000-1,999 other citations. Finally, Ireland, India, and Brazil had 650-999 other citations. The number of other citations for these 30 countries was 262,926 , accounting for 96.84 percent of all other citations, a notably high concentration (Figure 2).

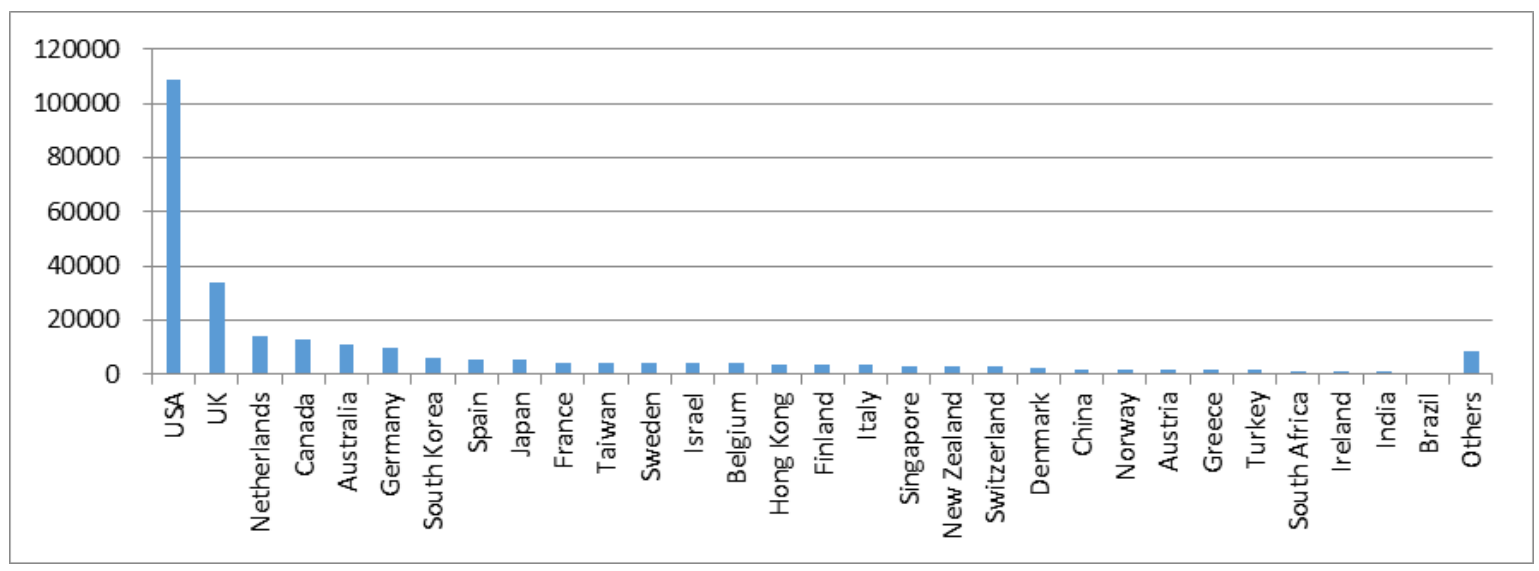

Figure 2: Total Other Citations of each Country (1996-2014)

\section{c) Competitiveness of International Leadership.}

Figure 3 shows that the Scopus database indexed 61 journals hosted by 5 countries in 1996 and 240 journals hosted by 28 countries in 2014 . The number of both journals and hosting countries showed rapid growth; however, the journals in the communication field were from a limited number of countries, revealing imbalanced regional distribution. For example, in 2014, the United Kingdom was the most competitive country in international leadership, with 100 indexed journals, of which 33 ranked as quartile-one journals. The 
United States had 64 indexed journals, including 21 quartile-one journals; the Netherlands had 22 indexed journals, with 4 quartile-one journals; Spain had 10 indexed journals, with 1 quartile-one journal; Germany had 8 indexed journals, with 1 quartile-one journal; Brazil, France, Sweden, Switzerland, Croatia, and Australia each had 2-5 indexed journals, none of which were quartile-one; and 17 other countries had 1 indexed journal which was not quartile-one. In addition, another 202 countries, including such large nations as Japan, China, India, South Africa, and Russia, had no indexed journals (Table 1).

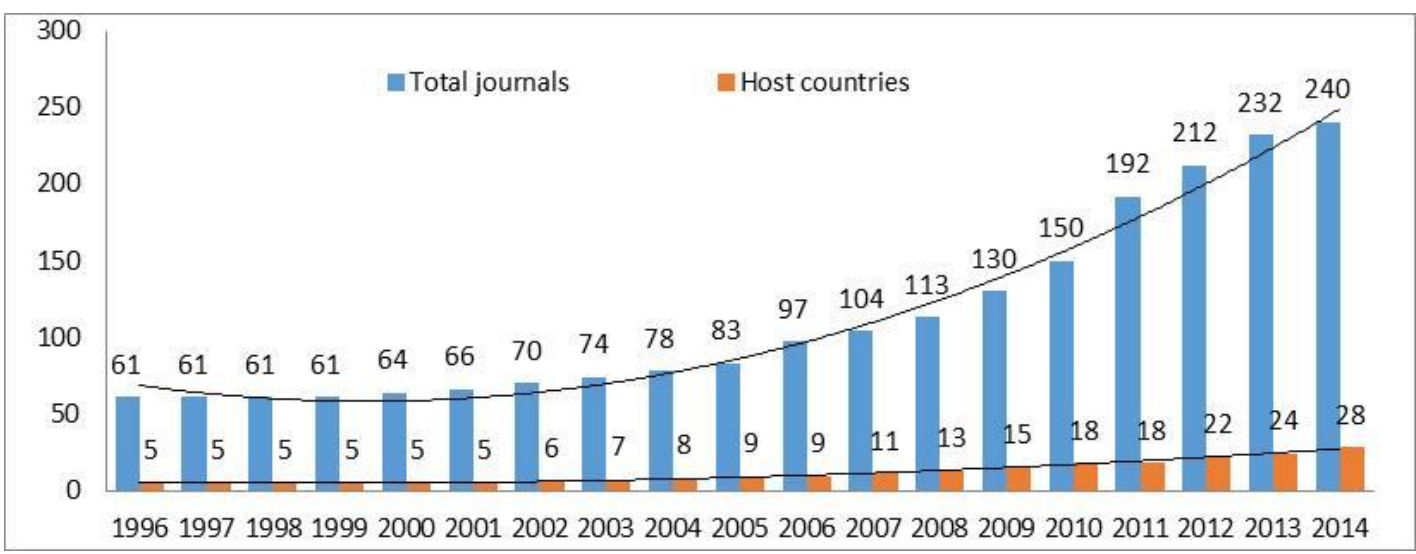

Figure 3: Total Number of Journals and Their Host Countries (1996-2014)

Table 1: Quartile and Distribution of Journals Indexed by the Scopus in 2014

\begin{tabular}{||c|c|c|c|c|c|c|c|c|c|c|c|c|c|}
\hline Quartile & UK & US & NED & ESP & GER & BRA & FRA & SWE & CHE & CRO & AUS & Other & Total \\
\hline Q1 & 33 & 21 & 4 & 1 & 1 & 0 & 0 & 0 & 0 & 0 & 0 & 0 & 60 \\
\hline Q2 & 21 & 16 & 7 & 3 & 4 & 1 & 0 & 1 & 1 & 0 & 1 & 5 & 60 \\
\hline Q3 & 25 & 12 & 6 & 2 & 0 & 3 & 1 & 2 & 0 & 2 & 0 & 7 & 60 \\
\hline Q4 & 21 & 15 & 5 & 4 & 3 & 1 & 3 & 0 & 2 & 0 & 1 & 5 & 60 \\
\hline Total & 100 & 64 & 22 & 10 & 8 & 5 & 4 & 3 & 3 & 2 & 2 & 17 & 240 \\
\hline$\%$ & 41.7 & 26.7 & 9.2 & 4.2 & 3.3 & 2.1 & 1.7 & 1.3 & 1.3 & 0.8 & 0.8 & 0.42 & 100 \\
\hline
\end{tabular}

Note: $\mathrm{NED}=$ Netherlands, $\mathrm{ESP}=$ Spain, GER $=$ Germany, BRA $=$ Brazil, FRA $=$ France, SWE $=$ Sweden, $\mathrm{CHE}=$ Switzerland, $\mathrm{CRO}=$ Croatia, $\mathrm{AUS}=$ Australia

\section{Integrated Competitiveness of Each Country}

Research question 2 focuses on the most recent status of countries' integrated competitiveness in international publication productivity. This study uses the most recent data, from 2014, to rank each country's ICI (the index includes the top 40 countries) (Table 2). The results show that, in 2014, the ICl of 113 countries could be divided into four tiers. Tier 1 consisted of only the country that held the leading position: The United States, with an index value of 7.76. Tier 2 contained leading countries in dominant positions, including the United Kingdom, the Netherlands, Canada, Germany, and Australia, with competitiveness index values of $4.40,2.16,1.40,1.33$, and 1.31, respectively. Tier 3 comprised 22 countries with great potential, including Spain, South Korea, France, India, and China, with index values of $0-1$. The gap between the second and third groups was not large. Tier 4 was composed of 85 relatively weaker, more academically marginalized countries, including Ireland, Turkey, Russia, Thailand, and Brazil, with index values of less 
than 0. Among Tier 4 countries, Turkey and Brazil published relatively large numbers of international papers, but due to their low number of other citations, their overall competitiveness remained in a disadvantaged position.

Table 2: Global Competitiveness of International Productivity in the Communication Field $(1996-2004)$

\begin{tabular}{|c|c|c|c|c|c|c|c|c|c|c|c|}
\hline Country & $\begin{array}{c}\text { ICI } \\
1996\end{array}$ & $\begin{array}{l}\text { Rank } \\
1996\end{array}$ & $\begin{array}{c}\mathrm{ICI} \\
2014\end{array}$ & $\begin{array}{l}\text { Rank } \\
2014\end{array}$ & Change & Country & $\begin{array}{c}\text { ICI } \\
1996\end{array}$ & $\begin{array}{l}\text { Rank } \\
1996\end{array}$ & $\begin{array}{c}\text { ICI } \\
2014\end{array}$ & $\begin{array}{l}\text { Rank } \\
2014\end{array}$ & Change \\
\hline us & 5.74 & 1 & 7.76 & 1 & o & Austria & -0.27 & 13 & 0.25 & 21 & -9 \\
\hline UK & 1.11 & 2 & 4.40 & 2 & o & Singapore & -0.24 & 21 & 0.22 & 22 & -1 \\
\hline Netherlands & 0.17 & 5 & 2.16 & 3 & 2 & Finland & -0.18 & 13 & 0.17 & 23 & -10 \\
\hline Canada & 0.18 & 3 & 1.40 & 4 & -1 & Denmark & -0.24 & 22 & 0.13 & 24 & -2 \\
\hline Germany & 0.15 & 7 & 1.33 & 5 & 2 & Greece & -0.21 & 15 & 0.08 & 25 & -10 \\
\hline Australia & -0.11 & 11 & 1.31 & 6 & 5 & Norway & -0.28 & 25 & 0.05 & 26 & -1 \\
\hline Spain & -0.02 & 8 & 0.96 & 7 & 1 & Iran & - & - & 0.04 & 27 & - \\
\hline South Korea & 0.18 & 4 & 0.82 & 8 & -4 & Ireland & -0.28 & 26 & 0.04 & 28 & -2 \\
\hline France & -0.05 & 9 & 0.77 & 9 & o & New Zealand & -0.23 & 20 & -0.05 & 29 & -9 \\
\hline India & -0.22 & 17 & 0.72 & 10 & 7 & Turkey & - & - & -0.05 & 30 & - \\
\hline China & - & - & 0.60 & 11 & - & Russian & -0.30 & 28 & -0.07 & 31 & -3 \\
\hline Japan & 0.16 & 6 & 0.57 & 12 & -6 & Thailand & - & - & -0.08 & 32 & - \\
\hline Taiwan & -0.22 & 19 & 0.52 & 13 & 6 & Brazil & - & - & -0.08 & 33 & - \\
\hline Sweden & -0.12 & 12 & 0.50 & 14 & -2 & Chile & - & - & -0.11 & 34 & - \\
\hline Switzerland & -0.25 & 29 & 0.48 & 15 & 14 & Malaysia & -0.31 & 32 & -0.15 & 35 & -3 \\
\hline Israel & -0.22 & 16 & 0.40 & 16 & o & Nigeria & - & - & -0.17 & 36 & - \\
\hline South Africa & -0.28 & 27 & 0.36 & 17 & 10 & Hungary & - & - & -0.19 & 37 & - \\
\hline Belgium & -0.06 & 10 & 0.29 & 18 & -8 & Mexico & - & - & -0.19 & 38 & - \\
\hline Hong Kong & -0.21 & 14 & 0.28 & 19 & -5 & Slovenia & -0.30 & 31 & -0.20 & 39 & -8 \\
\hline Italy & -0.22 & 18 & 0.26 & 20 & -2 & Portugal & - & - & -0.21 & 40 & - \\
\hline
\end{tabular}

Note: Total number of countries/territories in $1996=39$; total number of countries/territories in $2014=113 ; \mathrm{ICI}=$ Integrated Competitiveness Index.

\section{Changes in Competitiveness from 1996 Compared to 2014}

Research question 3 focuses on the changes in competitiveness in international publication productivity in the communication field. The competitiveness index was calculated at 1996 and 2014, and the data from those two benchmark years were compared (Table 2). In 1996, the United States had an advantage in overall competitiveness, with an ICl of 5.74, far above that of the other countries. The United Kingdom was in the second place, with an $\mathrm{ICl}$ of 1.11, still 5 times less than that of the United States. Developed countries such as Canada, South Korea, the Netherlands, Japan, and Germany were also at the forefront (ICls of 0-0.2), while China, Brazil, Turkey, Mexico, and other developing countries were not included in the list. By 2014, the United States, the United Kingdom, the Netherlands, 
Germany, and Canada still dominated, but the index values of several developed countries had declined: the values of Greece, Japan, and Austria fell significantly, and Russia's competitiveness also weakened. Meanwhile, the integrated competitiveness of China, India, South Africa, and Brazil has improved significantly. Among these countries, India (listed in the top 10) and China (ranked eleventh) became important competitors in international publication productivity in communication studies.

Changes in international participation further support these observations. An analysis of statistics from 1996 to 2014 revealed trends in international publications in the communication field could be divided into four groups. The first group included leading regions with high productivity and stability. The world's largest, most stable regions in international productivity were North America and Western Europe. After 2013, the gap between the productivity of Western European and North American countries declined significantly. It appears that North America and Western Europe will continue to enjoy a strong advantage in international productivity of communication publications for the foreseeable future. The second group had areas with high productivity and low stability. The Pacific region (Southeastern Asia, Australia, and New Zealand) had higher overall productivity than North America from 2003 to 2007, but their productivity declined rapidly after 2010. Considering the English language background of this region, its productivity is expected to increase in the near future.

The third group included regions with low productivity and rapid growth. Asia had a low baseline for the total publications but showing an accelerating growth trend from 2012 to 2014. If this trend continues, the gap among Asian countries and European-and-American nations will likely further narrow in the future. The fourth group was composed of marginal areas with low productivity and slow growth, including Latin America, Eastern Europe, the Middle East, and Africa. Countries in these regions had not only low baseline academic productivity but also slow growth rates; so we predict that this group will continue to grow slowly in the foreseeable future.

Our statistical results also show many positive signals in the structure of competitiveness in international publication productivity. On the whole, the United States and United Kingdom were among the most productive countries in citable documents; however, in 2007, the number of citable documents by other countries exceeded that of the United States. Since 2010, the rates of citable documents from the United States and United Kingdom have risen at a relatively low speed, while the citable documents of other countries have increased rapidly.

The emerging economies - represented by BRICS - showed rapid growth in publication productivity and could become global hotspots for productivity growth in the communication field. The growth of the total publications by BRICS's countries occurred in three stages from 1996 to 2014. From 1996 to 2006, there were no significant differences in the number of publications by these 5 countries with low productivity and growth rates. From 2007 to 2012, Brazil held an overwhelmingly leading position for number of publications. During 2013 to 2014, China led, while India, Brazil, and South Africa had no obvious differences. The gap between the number of South Africa's publications with those of China, India, and Brazil also narrowed, indicating large growth potential. Russia, though, has long been ranked low in publication productivity and experienced declining competitiveness, possibly related to its unstable economic situation in recent years. 


\section{Main Factors Influencing Competitiveness}

Research question 4 is aimed at exploring the main factors affecting countries' integrated competitiveness in international publication productivity. Using the factors in the four dimensions examined (GDP, GDP per capita, share of global GDP, GERD, GERD as a GDP percentage, total population, R\&D personnel per 1 million people, literacy rate, and number of universities), stepwise multiple regression resulted in two models. Model 1 eliminated eight independent variables, leaving only one factor (GDP). Model 2 eliminated seven independent variables and retained GDP and total population (Table 3), which fits with the explanation of this research.

Overall, two factors had significant impact on countries' integrated competitiveness:

1) Countries' economic growth status (GDP) had very significant impacts $(p<0.001)$. A possible explanation is that higher economic growth status and total GDP led to greater demand for communication research, increasing academic productivity in the field. For example, GDP growth in China and India drove the rise in their international productivity to a certain extent. Conversely, a worsening economic status could negatively affect countries' academic productivity. For instance, during the 2008 financial crisis, international publications in the communication field decreased worldwide. The recent decline of productivity competitiveness in Greece and Japan might also be the result of economic downturns in these countries.

2) Human resources (total population) also had significant impacts $(p<0.01)$. A possible explanation is that countries with large populations tend to have multiple social classes and complex social conflicts, creating an urgent need for scientific communication research. Additionally, larger populations offer greater human resources, promoting the growth of international productivity.

Table 3: Main factors influencing Integrated Competitiveness Index (ICI)

\begin{tabular}{|c|c|c|c|c|c|c|c|}
\hline & Variables & Beta & $\mathrm{T}$ & Sig. & Tolerance & VIF & \\
\hline \multirow{2}{*}{$\begin{array}{l}\text { Adding } \\
\text { variables }\end{array}$} & GDP & .94 & $8.78^{* *}$ & .000 & .75 & 1.33 & \multirow{9}{*}{$\begin{aligned} R^{2} & =.681 \\
F & =39.42\end{aligned}$} \\
\hline & Population & -0.34 & $-3.21^{* *}$ & .003 & .75 & 1.33 & \\
\hline \multirow{7}{*}{$\begin{array}{l}\text { Removing } \\
\text { variables }\end{array}$} & GDP per capita & .186 & 1.80 & .081 & .76 & 1.31 & \\
\hline & GDP share & -21.03 & -.56 & .578 & 6.28 & 1.06 & \\
\hline & GERD & -.96 & -1.72 & .095 & .03 & 2.16 & \\
\hline & R\&D percent of GDP & .04 & .38 & .703 & .92 & 1.08 & \\
\hline & $\begin{array}{l}\text { Researchers per } \\
\text { thousand }\end{array}$ & .08 & .82 & .418 & .83 & 1.20 & \\
\hline & Literacy rates & -.08 & -.74 & .464 & .77 & 1.35 & \\
\hline & Number of universities & .28 & 1.46 & .154 & .22 & 4.53 & \\
\hline
\end{tabular}

$* \mathrm{p}<0.05, * * \mathrm{p}<0.01$

\section{CONCLUSION}

This study uses the data (1996-2014) in the Scopus database to examine countries' competitiveness in international publication productivity in the communication discipline. Based on the statistical results, we can draw the following three major conclusions. 
First, in the era of globalization, it is not only urgent but also feasible to evaluate the competitiveness of each country in the international publication productivity. Past evaluations have been limited to single nations (Hickson et al. 1993) or several countries within designated local regions (Paul and Mark 1999). However, as discussed, the globalization of the academic environment calls for a global perspective on evaluation. Since the 1980s, significant changes have occurred as the socio-ecological systems of academic research (Young et al. 2006) have undergone a profound transformation (Fahey and Kenway 2010), shifting from national perspectives to an international perspective. Furthermore, a growing number of studies crosses the territorial boundaries of the nationstate, and international publication has become a common phenomenon. Moreover, global evaluation has been made possible by the prospects of "the global village constructed by transnational corporations" (Zembylas and Vrasidas 2005, p. 67), the rising popularity of big data technology, and large-scale academic literature database platforms. These conditions have made it convenient for scholars to engage in global sharing and cooperation within the international academic community (Ogan et al. 2009). In the foreseeable future, international publication productivity is expected to increase exponentially, and no researcher will be able to stay apart from the international academic community. The big data of international publication productivity indicates an urgent need for globalized evaluations which can provide a better understanding of overall status of the international publication and their developing trends.

Second, in the international publication productivity of communication studies, there is a serious knowledge gap and a severe polarization among countries. Both individual and integrated competitiveness indexes confirm a structure of imbalance in global publication competitiveness: the first world featuring the United States in the unshakable leading position, the second world comprised of a small, elite club of Western European countries, and the third world consisting of a large family of weak, low-income, less competitive, marginalized countries. Clearly, countries' competitiveness in international publication productivity in communication studies, to a certain degree, accords with their political and economic power (Dirlik 1994) because the distribution structure of international publication productivity is highly consistent with the global economic system. However, there have been positive signs of possibly rebalancing the imbalance structure. The emerging economies, represented by BRICS, seem to represent a rapidly rising power, have a narrowing gap with the second tier, and are expected to change the global imbalance in international publication productivity. These trends indicate that the shift in the world's economic hotspots will lead to changes in the global knowledge innovation map. Although emerging countries have made enormous progress in international participation and impact, a wide gap remains in international leadership, and these countries have a long way to go before they can gain an advantage in overall competitiveness.

Third, this study proposes a comprehensive method to assess countries' competitiveness in international publication productivity. In the past two decades, the competitiveness of countries' academic output has attracted the attention of many scholars and organizations. In 2001, the American Institute for Scientific Information developed the Essential Science Indicators (ESI), an evaluation method based on the $\mathrm{SCl} / \mathrm{SSCl}$ database with six indicators: highly cited papers, hot papers, top papers, average citations per paper, category normalized citation impact, and research fronts (for definitions, see Huo 2003). In 2003, Shanghai Jiao Tong University developed another evaluation method, the Academic Ranking of World Universities (ARWU) with five indicators: Nobel laureates, highly cited researchers, articles published in Nature or Science, articles in $\mathrm{SCl} / \mathrm{SSCl}$, and academic 
performance per faculty (for a full discussion, see Nian and Ying 2005). These two indexes have been widely used and recognized in many countries in recent years.

Compared with the ESI and the ARWU, the 3 I Index has many advantages. First, existing evaluation methods use indicators in two dimensions that emphasize quantity and quality (Law, Wu and Liu 2014) but neglect countries' leadership in academic productivity. With this shortcoming in mind, we propose a multi-level method to evaluate countries' competitiveness in three dimensions. We complement quantity and quality indicators (international participation, international impact) with leadership as a new indicator for evaluation. We highlight the leadership role of countries' international publication productivity and regard the number of journals hosted by countries as an important indicator in evaluation. Second, past research has evaluated institutions' competitiveness in publication productivity in single dimensions, which makes it difficult to combine these different indicators into one index (Hou and Liu 2014). However, we find that countries' competitiveness in international publication productivity can either be evaluated individually or integratedly. Existing indexes are usually applicable to the natural sciences and engineering but not the humanities and social sciences. The 31 Index is not only applicable in the communication field but can also serve as a valuable method in other disciplines, including the natural sciences, engineering, humanities, and social sciences.

\section{Policy Implications and Limitations}

First, as the leaders among international publication, North American and Western European countries should provide academic assistance to small, poorer underdeveloped countries in Asia, Africa, and Latin America to enhance their knowledge innovation capacity. According to human capital theory, high-quality intelligence research is important knowledge capital for countries and is closely related to their economic growth and competitiveness (Van Stel, Carree and Thurik 2005). The 79 countries that still have no academic output in the communication field, though, should not be excluded from the international academic community. It is important to recognize the importance of cultural diversity in the social sciences, and international publication productivity should present a picture of pluralism rather than a monopoly by a handful of countries. The developed and BRICS countries should take more responsibility and increase academic assistance funds in government aid to help third-world countries overcome their limitations through international academic cooperation. In addition, more international cooperation programs between developed and developing countries are urgently needed.

Second, BRICS, Asian, African, and Latin American countries should work together to cultivate international academic journals. This study shows that, although BRICS have achieved substantial progress in international participation and impact capability, but their leadership capability remains weak. Emerging economies, such as China, India, Brazil, South Africa, and Russia, do not lack capital but severely lag behind in the establishment of international academic journals, which limits their integrated competitiveness. Governments and research institutions in these countries, therefore, should increase their investment in English academic journals. Medium and small countries in Asia, Africa, and Latin America could also sponsor international journals based on their academic specialties and expertise.

Third, according to the study results, economic growth status and human resources have significant impacts on countries' competitiveness in international academic productivity. Governments, therefore, should develop policies to promote sound economic growth, 
creating a favorable external environment for the production of international publications. In addition, they should attempt to increase GERD to stimulate enthusiasm among researchers and scholars. Moreover, governments should formulate relevant policies to increase the supply of human resources for academic research and to attract more talent to areas related to knowledge innovation, providing human resources support to increase competitiveness in international publication productivity.

This study has some limitations. First, due to the difficulties in data collection, we included only the top 40 competitive countries as the analytical samples in regression analysis, leaving a relatively small sample size. Future studies could corroborate the conclusions of this study by using a larger sample pool in the analysis. Second, countries' international output includes a variety of document types, such as international academic papers, books, international conferences, and doctoral dissertations. However, as mentioned above, this study examines only the number of internationally published papers due to the space limitation. Further research should consider other document types. Finally, although this research uses the Scopus, a full-text database with broad coverage of indexed journals in communication, which has inevitably missed many international papers written in other languages. Finally, although we tested four groups of factors that might influence the competitiveness of countries' international publication productivity, we could not exhaustively identify all the related factors, and many other possible factors need to be examined. As a result, the conclusions of this study are valid only within the range of the sample data and should be generalized or extended only with caution.

\section{ACKNOWLEGEMENTS}

This study was supported by China - Montenegro Government Science and Technology Cooperation Project [No.2014-2-3].

\section{REFERENCES}

Abramo, G., D’Angelo, C. A., and Caprasecca, A. 2009. Gender differences in research productivity: A bibliometric analysis of the Italian academic system. Scientometrics, Vol. 79, no. 3: 517-539.

Agasisti, T., Catalano, G., Landoni, P., and Verganti, R. 2012. Evaluating the performance of academic departments: An analysis of research-related output efficiency. Research Evaluation, Vol. 21, no. 1: 2-14.

Aldington Report. 1985. Report from the Select Committee of the House of Lords on Overseas Trade. London: HMSO.

Aw, B. Y., Roberts, M. J., and Winston, T. 2007. Export market participation, investments in RandD and worker training, and the evolution of firm productivity. The World Economy, Vol. 30, no. 1: 83-104.

Barker, L., Hall, R., Roach, D., and Underberg, L. 1979. An investigation of the quantity of articles produced in the communication discipline by institution: 1970-1978. Association for Communication Administration Bulletin, Vol. 30, no. 1979: 8-22.

Berchicci, L. 2013. Towards an open RandD system: Internal RandD investment, external knowledge acquisition and innovative performance. Research Policy, Vol. 42, no. 1: 117127.

Biesta, G. 2012. Knowledge/democracy: Notes on the political economy of academic publishing. International Journal of Leadership in Education, Vol. 15, no. 4: 407-419. 
Wu, F. \& Djurovic, G.

Bornmann, L. 2012. Measuring the societal impact of research. EMBO reports, Vol. 13, no. 8: 673-676.

Chesterman, C., Ross-Smith, A., and Peters, M. 2003. Changing the landscape? Women in academic leadership in Australia. McGill Journal of Education, Vol. 38, no. 3: 421-436.

Deeds, D. L. 2001. The role of RandD intensity, technical development and absorptive capacity in creating entrepreneurial wealth in high technology start-ups. Journal of Engineering and Technology Management, Vol. 18, no. 1: 29-47.

Dirlik, A. 1994. The postcolonial aura: Third World criticism in the age of global capitalism. Critical Inquiry, Vol. 20, no. 2: 328-356.

Fahey, J., and Kenway, J. 2010. International academic mobility: Problematic and possible paradigms. Discourse: Studies in the Cultural Politics of Education, Vol. 31, no. 5: 563575.

Feist, G. J. 1997. Quantity, quality, and depth of research as influences on scientific eminence: Is quantity most important?. Creativity Research Journal, Vol. 10, no. 4: 325335.

Garfield, E. 1972. Citation analysis as a tool in journal evaluation. Science. Vol. 178, no. 12: 471-497.

Grueber, M., and Studt, T. 2015. Global RandD Funding Forecast. Available at: http://www.innovacion.gob.cl/wpcontent/uploads/2014/01/2014_global_rd_funding_f orecast.pdf.

Hickson, M. III., Stacks, D. W., and Amsbary, J. H. 1989. An analysis of prolific scholarship in speech communication, 1915-1985: Toward a yardstick for measuring research productivity. Communication Education, Vol. 38, no. 3: 230-236.

Hickson, M. III., Stacks, D. W., and Amsbary, J. H. 1993. Active prolific scholars in communication studies: Analysis of research productivity, II. Communication Education, Vol. 42, no. 3: 224-233.

Hickson III, M., Stacks, D. W., and Bodon, J. 1999. The status of research productivity in communication: 1915-1995. Communications Monographs, Vol. 66, no. 2: 178-197.

Hirsch, J. E., and Jorge, E. 2005. An index to quantify an individual's scientific research output. Proceedings of the National Academy of Sciences of the United States of America, Vol. 102, no. 46: 16569-16572.

Hocking, J. E., Stacks, D. W., and McDermott, S. T. 2003. Communication research. Boston: Allyn and Bacon.

Hodgson, G. M., and Rothman, H. 1999. The editors and authors of economics journals: A case of institutional oligopoly?. The Economic Journal, Vol. 109, no. 453: 165-186.

Hou, M., Fan, P., and Liu, H. 2014. A ranking analysis of the management schools in Greater China (2000-2010): Evidence from the SSCl database. Journal of Education for Business, Vol. 89, no. 5: 230-240.

Huo, Y. 2003. Essential science indicators. Library and Information Service, Vol. 24, no. 4: 67-78.

Jia, H., Miao, W., Zhang, Z., and Cao, Y. 2016. Road to international publications: an empirical study of Chinese communication scholars. Available at: http://www.tandfonline.com/doi/abs/10.1080/01292986.2016.1242020?journalCode=r ajc20.

Jung, J. 2014. Research productivity by career stage among Korean academics. Tertiary Education and Management, Vol. 20, no. 2: 85-105.

Koizumi, T., and Kopecky, K. J. 1977. Economic growth, capital movements and the international transfer of technical knowledge. Journal of International Economics, Vol. 7, no. 1: 45-65. 
Koljatic, M., and Silva, M. 2001. The international publication productivity of Latin American countries in the economics and business administration fields. Scientometrics, Vol. 51, no. 2: 381-394.

Law, R., Wu, J., and Liu, J. 2014. Progress in Chinese hotel research: A review of SSCl-listed journals. International Journal of Hospitality Management, Vol. 42, no. 9: 144-154.

Liu, Z. Y., and Shen, W. Q. 2011. China international publication productivity and its main influential mechanism (1987-2007). Education Journal of Renmin University, Vol. 2, no. 5: 72-94. (In Chinese).

Moed, H. F., and Van Leeuwen, T. N. 1995. Improving the accuracy of Institute for Scientific Information's journal impact factors. Journal of the American Society for Information Science, Vol. 46, no. 6: 461-467.

National Competitiveness Council (NCC). 2003. Annual Competitiveness Report 2003. December 01, 2003. Available at: http://www.competitiveness.ie/Publications/2003/ Annual-Competitiveness-Report-2003.html.

Nian C. L., and Ying C. 2005. The academic ranking of world universities. Higher Education in Europe, Vol. 30, no. 2: 127-136.

Ogan, C. L., Bashir, M., Camaj, L., Luo, Y., Gaddie, B., Pennington, R., and Salih, M. 2009. Development communication: The state of research in an era of ICTs and globalization. International Communication Gazette, Vol. 71, no. 8: 655-670.

Paasi, A. 2005. Globalisation, academic capitalism, and the uneven geographies of international journal publishing spaces. Environment and Planning A, Vol. 37, no. 5: 769-789.

Paul W. and Mark T. 1999. Knowledge-intensive services and international competitiveness: a four country comparison. Technology Analysis and Strategic Management, Vol. 11, no. 3: 391-408.

Population Division of the United Nations Department of Economic and Social Affairs. 2014. Population and Development Database 2014. Sept. 22, 2014. Available at: http://www.un.org/en/development/desa/population/publications/development/popu lation-development-database-2014.shtml.

Ritzberger, K. 2008. A ranking of journals in economics and related fields. German Economic Review, Vol. 9, no. 4: 402-430.

Ranking Web of Universities. 2016. Countries arranged by Number of Universities in Top Ranks, July 2016, Available at: http://www.webometrics.info/en/node/54.

SCImago. 2015. SJR SCImago Journal and Country Rank. October 28, 2015. Available at: http://www.scimagojr.com.

Teodorescu, D. 2000. Correlates of faculty publication productivity: A cross-national analysis. Higher Education, Vol. 39, no. 2: 201-222.

Tien, F. F., and Blackburn, R. T. 1996. Faculty rank system, research motivation, and faculty research productivity: Measure refinement and theory testing. The Journal of Higher Education, Vol. 67, no. 1: 2-22.

Tyson, L D'A. 1992. Who's bashing whom? Trade conflicts in high-technology industries. Washington DC: The Institute for International Economics.

UNESCO 2015, UNESCO eAtlas of Literacy, Dec. 4, 2016. Available at://tellmaps.com/uis/literacy/.

Van Stel, A., Carree, M., and Thurik, R. 2005. The effect of entrepreneurial activity on national economic growth. Small Business Economics, Vol. 24, no. 3: 311-321.

Watermeyer, R. 2014. Issues in the articulation of "impact": The responses of UK academics to "impact" as a new measure of research assessment. Studies in Higher Education, Vol. 39, no. 2: 359-377.

World Bank. 2014. World Bank's annual economic growth reports, July 22, 2014. Available at: http://data.worldbank.org/. 
Young, O. R., Berkhout, F., Gallopin, G. C., Janssen, M. A., Ostrom, E., and van der Leeuw, S. 2006. The globalization of socio-ecological systems: An agenda for scientific research. Global Environmental Change, Vol. 16, no. 3: 304-316.

$\mathrm{Yu}, \mathrm{X}$., and Gao, Z. 2010. An updated ranking of the economic research institutions in China (2000-2009). China Economic Review, Vol. 21, no. 4: 571-581.

Zainab, A. N. 1999. Personal, academic and departmental correlates of research productivity: a review of literature. Malaysian Journal of Library \& Information Science, Vol. 4, no. 2: 73-110.

Zembylas, M., and Vrasidas, C. 2005. Globalization, information and communication technologies, and the prospect of a "global village": Promises of inclusion or electronic colonization?. Journal of Curriculum Studies, Vol. 37, no. 1: 65-83. 